Geophysics

\title{
Continental area and elevation
}

from A.G. Smith

WHEN all the continents were clustered together as Pangea, a small part of that supercontinent experienced flooding by the sea. By contrast, a much larger area of the smaller continents created by the breakup of Pangea has undergone periodic flooding during global rises in sea level. Because there is no reason to suppose that similar changes in sea level did not take place when Pangea existed, an important aim of geophysicists has been to explain the different flooding frequencies before and after the break-up.

Analyses of the global topography suggest that continental area is correlated with continental height. From this it follows that Pangea, the largest possible continent, would have had the largest average height, thereby reducing the area available to flooding during a global rise in sea level. Two authors ${ }^{1,2}$ have recently reassessed the suggested area-height relationship.

On page 370 of this issue of Nature, Wyatt ${ }^{1}$ discusses some of its implications. In particular, he suggests that the reduction in shelf area that might be expected to have accompanied the formation of Pangea may have been a casual factor in the late Permian extinctions of shelf organisms. Stanley, however, has cited evidence that geologically recent reductions in shelf areas have had little effect on some shallow-water faunas ${ }^{3}$.

In a recent paper $\mathrm{Cogley}^{2}$ makes a more detailed analysis of continental topography, particularly continental margins, than the analyses by Harrison and others 4,5 on which Wyatt's paper is based. Cogley concludes that modal height - as opposed to average height - is not correlated with continental area.

He cites several areas that are much higher than any height-area relationship based on the major continents would predict, including Arabia and India. The tiny mountainous islands of Corsica and Sardinia in the Mediterranean are also anomalous, though this is not unexpected as they are associated with young mountain-building movements. However, were Madagascar regarded as a distinct continent, it too would be anomalously high. It would seem that the correlation of continental elevation with continental area is not as clear as one might like.

Until one has a working model of what determines the thickness of continental crust and why it should change with area, it is difficult to know whether these exceptions are important. In the case of the oceans, there is an excellent quantitative understanding of the relationship between ocean-floor depth and age ${ }^{5}$. Anomalously shallow ocean floor is simply a place where more molten rock has erupted or been injected into the crust than normal. Why this should have happened is not clear, but at least the unexpected increase in thickness is explained.

In the case of the continents there is no generally accepted working model of what determines the thickness of their crust. A suggested mechanism of continental uplift is the injection of carbon dioxide and water into the lower crust, but the volumes involved are so huge that such an explanation seems unlikely, except on a local scale.

The only plausible cause is physical. Analogy with the oceans suggests that the most probable mechanism is an increase in heat flow. This could cause uplift simply by bringing about the thermal expansion of the continental lithosphere. Furthermore, the heat could effect crystalline phase changes in the rock minerals, inducing significant volume changes without any change in bulk composition. Uplift associated with uprising convection currents would be unlikely to be as much as the hundreds or thousands of metres observed in, for example, southern Africa. But one can speculate that convection might be more vigorous under large continents and

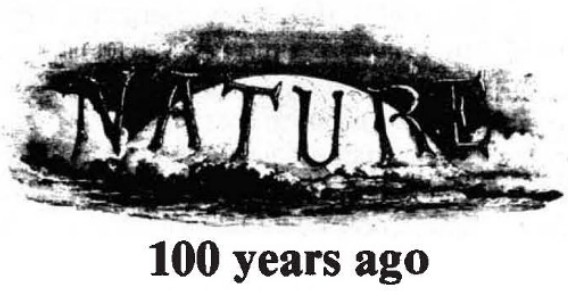

THE Japanese appear to be determined to render themselves, as far as possible, independent of foreign countries. They have, says the Pharmaceutical Journal, established in Tokio a factory for the production of pharmaceutical chemicals on a large scale. A company with a capital of about $40,000 l$. has been formed for this purpose. Of this amount the Government has contributed one-half free of interest for twenty years, besides making a free grant of land and erecting the necessary buildings. A similar company is taking up the utilisation of the waste saké from the native breweries in the manufacture of alcohol, and the manufacture of bleaching-powder on a large scale has been commenced. Whether with the object of "protecting" the first of these enterprises or not does not appear, but we learn from the same authority that an increased tax has been placed in Japan on imported patent medicines, and the nature of the articles to which this has been extended is stated to have largely affected the import of some chemicals into that country. Santonin, which was at one time much in request among the Japanese, decreased 20,000 ounces in import last year, although the price was lower; on the other hand, the consumption of quinine showed and increase.

From Nature 30, 512, 25 September 1884. deliver more heat, and this might partly explain the correlation between area and height.

How can these problems be resolved? An important approach will be to document precisely the changes in continental structure with time. One of the most promising sources of information is the rock fragments brought up from great depths in diamond pipes. It might be possible to infer a continental lithospheric structure from a suite of fragments from an old pipe that is know to have penetrated a continent when it was near sea level and compare it with a suite from a younger pipe that penetrated that continent when it stood at a much higher level. Southern Africa may hold the key to this approach.

It is ironic that our understanding of the continents on which we live is far less advanced that our understanding of the ocean floor, which we rarely see. Discussion of the implications of the correlation between continental area and elevation will help to point the way to changing this state of affairs.

\footnotetext{
Wyatt, A.R.Nature 311, 370 (1984).

Cogley, J.G. Rev, Geophys, Space Phys. 22, 101 (1984).

3. Stanley, S.M. Geology 12, 205 (1984)

Harrison, C.G.A. et al. Earth planet. Sci. Lett. 54, 1 (1981).

Harrison, C.G.A., Miskell, K.J., Brass, G.W. Saltzmann, K.S. \& Sloan, J.L. Tectonics 2,35? (1983)

6. Sclater, J.G. \& Parsons, B. J. geophys, Res. 82, 803 (1977)
}

A.G. Smith is in the Department of Earth Sciences, University of Cambridge, Downing Street, Cambridge CB2 $3 E Q$.
A fRIEND of mine, Capt. W. Hopkins, of the schooner Mary Ogilvie, who has just returned from a voyage all round Australia, has given me the following information, which I forward you for publication, not so much because of its interesting character, but in order that other travellers may throw some light upon the character of the animal, which, if an Octopus, must be of much larger dimensions than those usually met with. On June 15 , when in S. lat. $21^{\circ}$ $37^{\prime}$ and E. long $.13^{\circ} 49^{\prime}$, about five miles of $f$ the Exmouth Gulf on the western coast of the continent, he saw an immense creature which he took to be a species of Octopus. His attention was drawn to it by a perfect cloud of sea birds, and at first he naturally thought it must be a dead carcass. On approaching it, however, he found it was alive and sluggishly disporting itself. In shape it was like a violin, but of immense size, with some six feelers about the greater diameters of the violin. It lay almost flat upon the water, was of a dark gray above and lighter gray below, and was continually elevating one of its feelers, apparently twice the thickness of a man's arm, to a height of from six to eight feet. It appeared to be vomiting, and as the birds were evidently feeding, that accounted for their presence in such numbers. Its size was so great that, had it grasped the vessel, it could easily have capsized it. The captain therefore got out of the way as quickly as possible, and without making definite measurements; but a large whale in the vicinity looked quite diminutive. It is a pity that something more exact as to size is not available, but I think the description is sufficient to convey an idea of the nature of the monster. 